\title{
Compulsive gambling in the financial markets: Evidence from two investor surveys
}

\author{
Ruben Cox ${ }^{a}$, Atcha Kamolsareeratana ${ }^{\text {b }}$, Roy Kouwenberg b,a,* \\ a Erasmus University Rotterdam, Burgemeester Oudlaan 50, 3062 PA Rotterdam, The Netherlands \\ ${ }^{\mathrm{b}}$ College of Management, Mahidol University, 69 Vipawadee Rangsit Rd., 10400, Bangkok, Thailand
}

\section{A R T I C L E I N F O}

\section{Article history:}

Received 30 April 2019

Accepted 20 November 2019

Available online 22 November 2019

\section{JEL classification:}

G11

G02

L83

\section{Keywords:}

Individual investors

Trading behavior

Gambling

\begin{abstract}
A B S T R A C T
This study shows that a group of individual investors in the financial markets displays symptoms of compulsive gambling, or an addiction to trading, based on a standard diagnostic checklist from the American Psychiatric Association. In a representative sample of Dutch retail investors, we find that $4.4 \%$ of the investors meet the criteria for compulsive gambling in the financial markets. Another $3.6 \%$ meet the criteria for problem gambling, which is a less severe form of gambling disorder. Investors with symptoms of compulsive gambling problems tend to follow a more active and speculative trading style, indicated by a higher frequency of stock trading, day-trading and investing in derivatives and leveraged products.
\end{abstract}

(c) 2019 Elsevier B.V. All rights reserved.

\section{Introduction}

In this paper we adopt a diagnostic checklist from the American Psychiatric Association (APA) to assess how many individual investors in the financial markets show symptoms of gambling disorder, a behavioral addiction to trading financial products. There is a rich literature on individual investor behavior showing that some retail investors actively trade stocks, options and speculative products such as Bitcoin, even though frequent trading typically leads to poor portfolio returns. ${ }^{1}$ Barber and Odean (2000; 2001) argue that these investors are overconfident and overestimate the precision of their private information. Another explanation is that investors simply trade actively because they like it (Black, 1986) and directly derive non-financial utility from their trading activities. For example, some investors could be trading as a form of entertainment, or gambling (Dorn and Sengmueller, 2009; Grinblatt and Keloharju 2009; Kumar, 2009; Dorn et al., 2015; Gao and Lin, 2015).

\footnotetext{
* Corresponding author at: Mahidol University, College of Management, 69 Vipawadee Rangsit Rd., 10400, Bangkok, Thailand.

E-mail addresses: roy.kou@mahidol.ac.th, kouwenberg@ese.eur.nl

(R. Kouwenberg).

1 See Odean (1999), Barber and Odean (2000), Bauer, Cosemans and Eichholtz (2009), Entrop et al. (2014) and Hoffmann and Shefrin, (2014), amongst others.
}

Statman (2002) and Kumar (2009) argue that investors can use stock trading as a direct substitute for traditional forms of gambling such as lotteries, casinos and sports betting. Speculation in financial markets offers large payoffs and provides investors with immediate feedback about gains and losses. This is similar to conventional forms of gambling, but arguably with better odds of winning and with lower fees (Arthur et al., 2016). Kumar (2009) shows that individual investors who prefer speculative stocks tend to have the same socio-demographic profile as gamblers. Evidence that trading can be used as a substitute for gambling comes from studies that document a significant decrease in stock trading volume by individual investors on days with drawings of large lottery jackpots (Dorn et al., 2015; Gao and Lin, 2015). Further, Mills and Nower (2019) report that more than half of frequent gamblers in the U.S. also trade crypto-currencies like Bitcoin.

One concern about trading as a form of gambling is that it may become problematic, or even compulsive for a small subgroup. The literature shows evidence of people seeking treatment for an addiction to trading in studies conducted in gambling clinics around the world, including Spain (Granero et al., 2012), France (Grall-Bronnec et al., 2017), and Korea (Shin et al., 2015). Youn et al. (2016) developed a compulsive trading as gambling scale that they fielded in a survey among Korean individual investors. They report that $21.5 \%$ of Korean investors meet the criteria for compulsive gambling. Further, Kamolsareeratana and Kouwenberg (2019) find that $14.4 \%$ of a sample of retail investors in Thailand 
display symptoms of compulsive or problematic gambling in the stock market. In addition, Dorn and Sengmueller (2009) find that two survey items that identify compulsive gamblers are associated with excessive portfolio turnover among German retail investors.

In this paper we use two unique investor survey datasets to measure the proportion of individual investors in the Netherlands that show symptoms of compulsive gambling in the financial markets. The purpose is to investigate the existence and prevalence of compulsive gambling in the financial markets. Further, we validate the trading addiction screen by testing if it is associated with more frequent and speculative trading behaviors, such as a higher stock trading frequency, day trading and investing in derivatives and leveraged products. In addition, we test if compulsive gambling is associated with a deteriorating financial situation, such as accumulating debt or struggling to pay bills on time.

The psychiatric literature defines compulsive gambling as persistent and counter-productive gambling behavior (APA, 2013). Compulsive gamblers have an irresistible urge to place bets, regardless of the losses and other negative consequences that the gambling activities cause in their life. Evidence from gambling clinics shows that in extreme cases trading as gambling can also become addictive, to the point where medical treatment is needed (Granero et al., 2012; Shin et al., 2015; Grall-Bronnec et al., 2017). In our investor surveys we field a standard measure for compulsive gambling from the American Psychiatric Association, which screens for nine symptoms of compulsive gambling behavior. Typical symptoms of compulsive gambling are having difficulty to stop gambling, lying to hide involvement with gambling, and jeopardizing relationships or career opportunities because of gambling.

In our representative sample of Dutch investors, we find that $4.4 \%$ of the investors show symptoms of compulsive gambling, or in other words a trading addiction. Furthermore, another 3.6\% of the investors can be categorized as problem gamblers, which is less severe than compulsive gambling but still excessive and potentially problematic. As a validation of the trading addiction scale, we confirm that it is associated with more active and speculative trading styles, even after controlling for other relevant factors such as overconfidence and high risk tolerance. In addition, investors displaying compulsive gambling symptoms tend to be in a significantly worse financial situation compared to investors with an otherwise similar demographic profile.

An effective screen for compulsive gambling in the financial markets should identify investors with serious gambling problems, while excluding those who simply enjoy a speculative trading style without having issues. For this reason, the survey also included four other measures for the gambling motives of investors, to contrast and compare with the compulsive gambling screen. A well-known motive for gambling is sensation seeking, taking risks just for the sake of the experience and the thrill of it (Zuckerman, 1994). A second gambling motive is the aspiration for riches, the small chance that trading offers to quickly gain relatively large amounts of money (Conlisk, 1993). Our survey included two questions asking the investors whether they mainly trade for the fun and challenge of it, or to chase a small chance to become rich. We also assess the investors' gambling motives indirectly, by measuring the propensity to engage in conventional gambling activities. In our survey we asked investors if they gambled in the last 12 months, such as in casinos, sports betting, and on slot machines. In addition, we measure the DOSPERT gambling risk-taking scale (Weber et al., 2002), a proxy for the propensity to gamble with real money at stake.

Our results show that more innocuous gambling motives for trading, such as trading for fun (44.7\%) or for a small chance to become rich (13.4\%), are more widespread than compulsive gambling disorder in the financial markets (4.4\%). Further, investors with these two gambling motives trade less actively than compulsive gamblers, and they are in a similar financial situation as other investors. Investors that sometimes gamble outside the financial markets (casinos, slot machines, sports betting, or card games) do tend to display more active and speculative trading behavior, and are in a slightly worse financial situation on average, but not to the same extent as trading addicts. These results confirm that the compulsive gambling screen is exclusive, and not just picking up any investor with gambling motives.

This paper is the first in the literature to estimate how pervasive compulsive gambling in the financial markets is for a representative sample of individual investors, contributing to the literature on gambling disorders. Moreover, we complement the evidence in Dorn et al. (2015) and Gao and Lin (2015), who use lotteries as natural experiments to demonstrate a relation between gambling desires and individual investor trading, by using a survey approach to directly identify investors who gamble in the financial markets. Our findings corroborate with the fun and excitement hypothesis in Gao and Lin (2015), as many investors reveal in our survey that they trade financial products for fun or a small chance to become rich as if they are gambling, while a small group display symptoms of compulsive gambling. Our study of Dutch investors also contributes to the literature on individual investor trading behavior, adding another piece of evidence to earlier work that focused on Taiwan (Gao and Lin, 2015), Germany and the U.S. (Dorn et al., 2015).

In addition, we validate the compulsive gambling screen adopted for trading financial products, by showing that it is associated with more speculative trading styles and a higher incidence of financial problems. We demonstrate that the compulsive gambling screen is exclusive and isolates a relatively small group of investors. Our results are relevant for brokers and policy makers, because compulsive gambling is known to have large negative effects on people's wealth, health and family relations, with substantial costs for society as a whole. Gerstein et al. (1999) estimate the costs of pathological gambling in the US alone as 4.7 billion dollar annually. Screening for compulsive gambling in the financial markets may help to identify those investors who are most at risk of developing unsustainable trading behavior. In addition, in the past decade highly speculative leveraged products and crypto-currencies have become available to individual investors in unregulated offshore markets. Some of these new financial products facilitate gambling on short-term price movements with investment horizons as short as a few seconds (see Fig. 1), which could attract people with gambling problems (Arthur et al., 2016; Mills and Nower, 2019).

Although trading as gambling may only concern a small number of retail investors, it can also materially affect prices in the financial markets due to the disproportional trading volume and coordination by gamblers. For example, Han and Kumar (2013) find that lottery-type stocks favored by retail investors with high gambling propensity are overpriced, Kumar et al. (2016) show that trading by gambling-motivated investors generates excess return comovement among stocks with lottery features, and Bali et al. (2017) argue that the low beta anomaly can be explained by retail investors' demand for lottery-like stocks.

\section{Gambling motives for trading}

Prior studies argue that some investors may enjoy gambling in the financial markets (Dorn and Sengmuller, 2009; Kumar, 2009), in the same way that people enjoy buying lottery tickets and gambling in casinos. However, for some investors trading as a form of gambling may become compulsive (Granero et al., 2012; Shin et al., 2015; Youn et al., 2016; Grall-Bronnec et al., 2017), and our main objective is to measure the prevalence of compulsive gambling in a representative sample of Dutch investors. The measure 


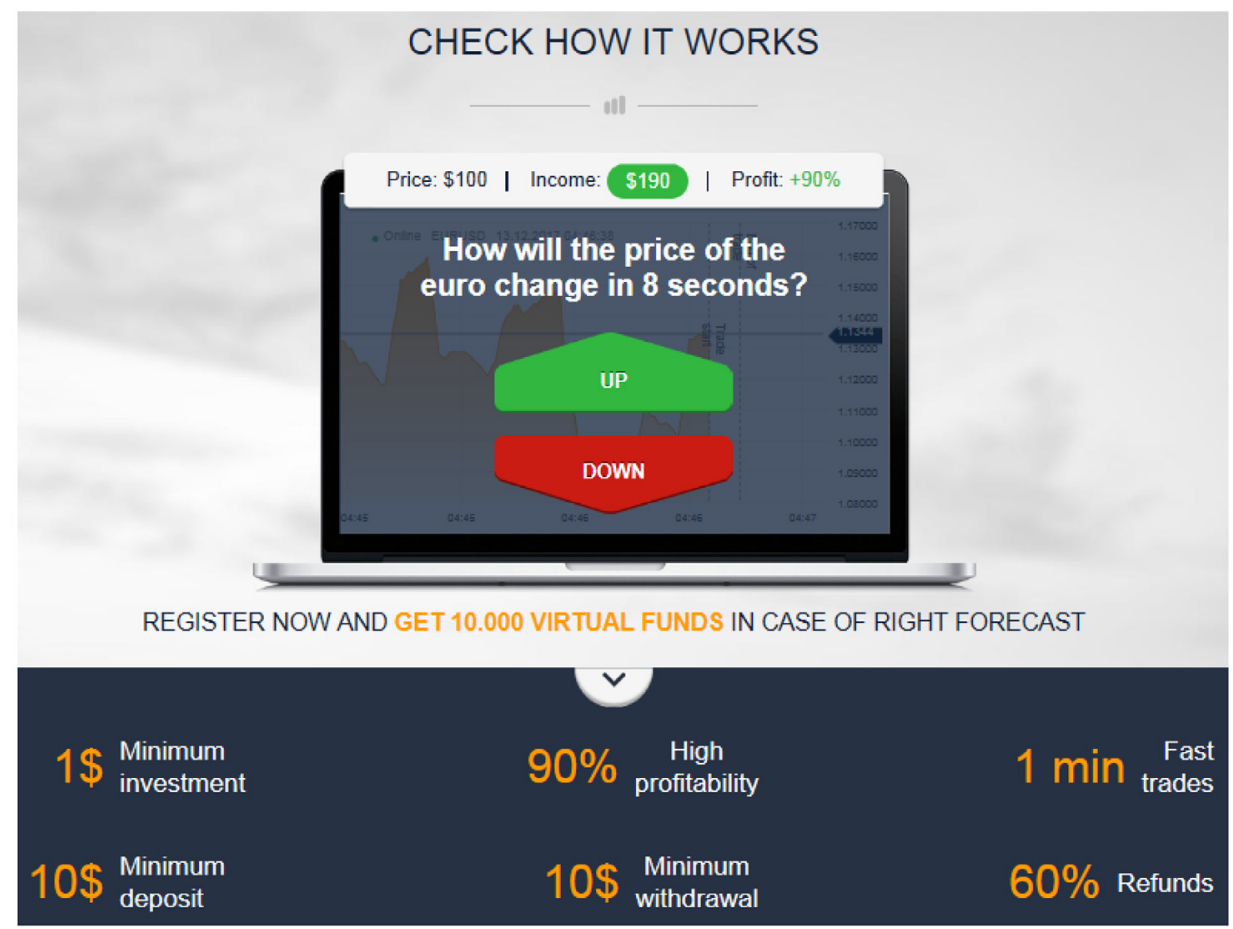

\section{Click. 60 seconds. Up to 85\% profitability.}

\section{Start trading Binary Options right now!.}
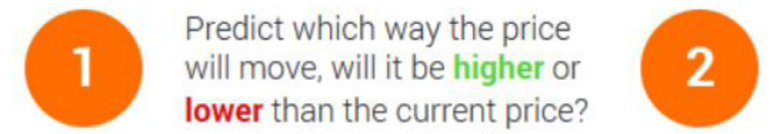

Gain up to $\mathbf{8 5 \%}$ for a correct

prediction

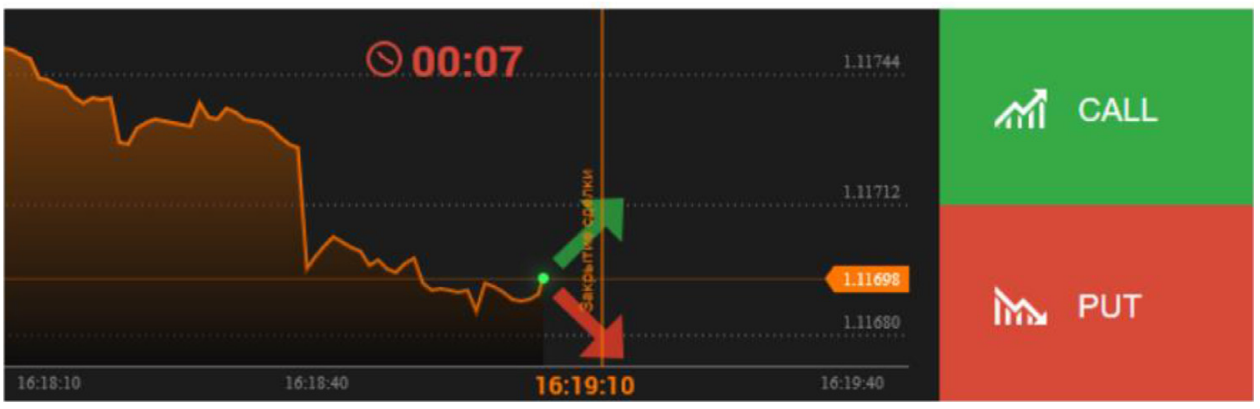

Fig. 1. Example of an advertisement for a binary option.

Source: Olymp Trade, Binary Options Broker. https://olymptrade.com/lands/LPL09-03-01en/.

for compulsive gambling in the financial markets is explained in Section 2.1 below.

Further, in this section we review the literature on the gambling motivations that investors might have for trading in financial markets, such as trading for fun and trading to become rich quickly. We also describe our direct and indirect measures for these gambling motives. Our purpose is to see if the group of compulsive gamblers in the financial markets is smaller than the group of investors with these more innocuous gambling motives, and whether the trading behaviors and financial problems of the trading addicts are more extreme.

\subsection{Compulsive gambling}

It is well-established in the psychiatric literature that for a small group of people gambling can become excessive and problematic. Compulsive gambling is defined as 'persistent and recurrent counter-productive gambling behavior' and characterized by the inability to control the urge to gamble (APA, 2013). This can ultimately have harmful consequences, such as financial difficulties, health issues and relationship problems (Blaszczynski and Nower, 2002). Youn et al. (2016) and Kamolsareeratana and Kouwenberg (2019) provide evidence that some individual 
investors in Korea and Thailand display symptoms of compulsive gambling behavior in the stock market. Compulsive gambling is often accompanied with other serious problems, such as depression, substance use and financial difficulties. Related, Engelberg and Parsons (2016) show that stock market declines almost instantly impact the physical health of some investors, as hospitalization rates for mental health problems such as anxiety and depression increase significantly over the next two days. This underscores the importance to distinguish compulsive gambling from other less harmful gambling activities.

Psychiatrists typically use the Diagnostic and Statistical Manual of Mental Disorders, DSM-5, of the American Psychiatric Association (APA, 2013) to diagnose compulsive gambling. It defines nine symptoms, such as "Needs to gamble with increasing amounts of money in order to achieve the desired excitement" and "Has made repeated unsuccessful efforts to control, cut back, or stop gambling". A person displaying at least four out of nine symptoms is typically classified as a compulsive gambler (APA, 2013).

Following Youn et al. (2016), we adapt the DSM-5 diagnostic criteria to measure compulsive gambling behavior in the financial markets by replacing the word 'gambling' with 'trading financial products': see Appendix A. We use scores of four and higher on the nine DSM-5 questions as an indicator for compulsive gambling in the financial markets. Respondents with a score of three symptoms are considered to be problem gamblers (Welte et al., 2015), which is a less severe form of gambling disorder (Volberg, 2001). We note that a survey measure only provides an indication of potential gambling problems, while actual diagnosis of compulsive behavior involves multiple observations by a psychiatrist. However, that being said, it is standard practice in the gambling literature to estimate the prevalence of compulsive gambling in the population with survey questions based on APA DSM diagnostic criteria (see, for example, Stucki and Rihs-Middel, 2007, and Welte et al., 2015)

\subsection{Motives for gambling in the stock market}

Apart from compulsive trading as gambling, investors may also have more innocuous motivations for gambling in the financial markets, such as trading for fun, or for a small chance to become rich. Our survey also included several other questions to measure the investors' gambling motives, both directly and indirectly.

\subsubsection{Sensation seeking motive}

Sensation seeking is a personality trait where individuals take risks just for fun or the thrill of the experience (Zuckerman, 1994). Horvath and Zuckerman (1993) document that sensation seeking is positively related to risky behavior in many domains, including gambling and financial risk-taking. Grinblatt and Keloharju (2009) find that sensation-seeking investors tend to trade more frequently, using the number of speeding tickets as a proxy for the trait. Dorn and Sengmueller (2009) use survey questions to elicit if retail investors trade for fun and entertainment, and they find that those who enjoy trading tend to have a portfolio turnover rate that is twice those of other investors. We follow the approach of Dorn and Sengmueller (2009) and measure the sensation seeking motive by an indicator variable equal to one if the respondent mentions that "the fun or the challenge of investing" is among his investment objectives. See Appendix A for the survey questions.

\subsubsection{Gambling to become rich motive}

Statman (2002) and Dorn and Sengmuller (2009) argue that investors might also actively trade stocks to pursue a small chance to become rich, similar to lottery players. Related, Kumar (2009) shows that especially low-income investors tend to trade "lottery stocks" that offer a small chance of realizing an extreme positive return. In addition, Kumar (2009) demonstrates that the trading volume of lottery stocks tends to rise during economic downturns when wealth levels are depressed. Kahneman and Tversky (1979) document that when wealth falls below a person's aspiration level, or reference point, it can trigger risk-seeking behavior. We measure the wealth aspiration gambling motive by a dummy variable that equals one if investors indicate that their investment objective is "to give me a small chance to get rich, and I am willing to take risk for this purpose" (see Appendix A).

\subsubsection{Conventional gambling activities as an indirect proxy for gambling motives}

Recent studies argue that stock market trading is sometimes used by investors as a substitute for participating in conventional gambling activities, such as lotteries, casinos and sports betting (Kumar, 2009; Dorn et al., 2015; Gao and Lin, 2015). Similar to conventional forms of gambling, speculating in the financial markets can offer large payoffs with instant feedback about gains and losses. Gao and Lin (2015) and Dorn et al. (2015) show that stock trading volume by individual investors decreases substantially on days when large and salient lottery jackpots are drawn. For example, the trading volume of Taiwanese stocks that are likely to attract individual traders drops up to $7 \%$ on large jackpot days (Gao and Lin, 2015).

To measure the gambling motives of investors indirectly, we use a survey question asking investors if they participated in any of the following conventional gambling activities over the last twelve months: playing slot machines, gambling in casinos, online gambling, sports betting and playing in real money poker games. However, a potential drawback of this measure is that it neither considers the amount of risk individuals are willing to take when gambling, nor how likely it is they will gamble again in the future. Therefore, as a second measure we use the DOSPERT gambling risk-taking propensity scale of Weber et al. (2002), applied previously by Markiewicz and Weber (2013) to explain trading volume in an experimental market. The first question of the DOSPERT-scale asks: "How likely is it that you will participate in the following activities? Betting with 100 euro or more on a slot machine." The question is answered on a 5-point scale ranging from "Very unlikely" to "Very likely". Three similar questions follow about betting with 100 euro or more in a casino, on a sports game, or on a poker game (see Appendix A). The DOSPERT scale is the average of the four responses, ranging from 1 to 5 . We also construct a gambling propensity dummy equal to one if the respondent has a score of 3 or higher on at least one of the four questions, showing some tendency to gamble with real money at stake.

\section{Data}

\subsection{Investor surveys}

Our data was collected in 2017 using two different panels of Dutch individual investors. The first panel is the Dutch National Bank Household Survey (DHS) which is operated by CentERdata, a research institute affiliated to Tilburg University specialized in socioeconomic research. Our second dataset is obtained via a panel of the Dutch Authority for Financial Markets (AFM).

The DHS panel contains 2300 members and is representative for the Dutch population. Members of the DHS receive a small compensation for each survey that they complete. We fielded a custom survey in the DHS in October 2017, targeting all 375 panel members who owned financial assets, as well as a reference group of 300 non-investors. We received a total of 619 responses. Our survey module asked "Do you invest (in financial assets)?", and 274 of the respondents classified themselves as investors. Out of these 274 investors, only 106 traded stocks, ETF's, derivatives or 
leveraged products themselves during the past twelve months. ${ }^{2}$ Our main analysis is based on this subsample of 106 direct investors, as our aim is to investigate speculative trading behavior and its relation with gambling problems.

We obtained additional data by fielding our survey in the AFM-panel in March 2017. The AFM is the Dutch equivalent of the United States Securities and Exchange Commission (SEC) and supervises the conduct of financial institutions in savings, investments, insurance and loan markets. The AFM regularly conducts surveys in its own panel of 1733 members. The panel is composed of individuals who previously contacted AFM with questions or complaints (40\%), members who enrolled voluntarily (10\%) and individuals recruited from a large representative panel managed by the market research company GfK (50\%). The AFM panel is not representative for the Dutch population because it overweighs individual investors, but this is suitable for our purposes. Our survey was distributed to all AFM panel members and within a week we received 866 responses, corresponding to a 50\% response rate. $^{3}$ Among the AFM respondents only 259 directly invest in stocks, ETF's, derivatives or leveraged products and are relevant for our study.

\subsection{Demographics of the investor samples}

Descriptive statistics of the socio-demographic variables for both the DHS and AFM sample are reported in Table 1 , as well as for the combined group of DHS and AFM investors. Significant differences in means or proportions between the two datasets are indicated by stars (*, ** and ${ }^{* * *}$ for $1 \%, 5 \%$ and $\left.10 \%\right)$. First of all, we note that the typical Dutch direct investor is a 60-year old man with a bachelor or master degree. ${ }^{4}$ Further, the large majority of investors (about 90\%) have more than five years of investment experience, while only one out five investors has access to a financial advisor. The two investor samples are similar in these key aspects, but also differ significantly on some others: investors in the AFM-panel are wealthier, have higher income and are more likely to be business owners.

\subsection{Control variables}

Our survey also includes measures for other key variables that can explain trading behavior based on the literature, namely risk tolerance, overconfidence and financial literacy. Risk tolerance is assessed using the general risk question of Dohmen et al. (2011) and measured on a 10-point scale ranging from 1 indicating "Not willing to take risks" to 10 being "Very willing to take risks". Financial literacy is measured by the "Big Three" financial literacy questions developed by Lusardi and Mitchell (2007), which were fielded in both the DHS and AFM panel. Our measure of financial literacy is the number of correct responses to the three questions, covering knowledge of interest, inflation and diversification (see Appendix A).

We also measure one type of overconfidence, namely the better-than-average effect (see Glaser and Weber, 2007). The survey asks the respondents to compare their investment abilities to the average investor on a 5-point response scale, ranging from 1 being "Much worse" to 5 "Much better". We create a dummy

\footnotetext{
2 The remaining 168 investors have delegated all their trading decisions to a broker, or they only invest in bonds, mutual funds or property, assets less prone to active and speculative trading.

${ }^{3}$ Panel members recruited by GfK receive compensation for their participation, while the voluntary enrolled AFM panel members participate in a semi-annual lottery to win a lunch with AFM's CEO.

${ }^{4}$ Less than $10 \%$ of the investors are younger than 35 years in the DHS, and less than $10 \%$ are younger than 45 years in the AFM panel. Female investors are almost absent: only $9 \%$ in the DHS and $6 \%$ in the AFM panel.
}

variable for the 'better-than-average' form of overconfidence that equals one if the investor indicates that his performance is just as good, better or much better than average, while having a financial literacy score that is below average.

\subsection{Trading behavior and financial situation}

Our survey includes several questions on trading behavior during the last 12 months. We use five variables to capture speculative trading behavior. Stock trading frequency measures the frequency at which the investor trades individual stocks on a 5-point scale: 1 = "I barely trade", $2=$ "1-10 times/year", 3= "1-10 times/month", 4= "3-4 times/week", 5= "almost every day". We construct a dummy for High stock trading frequency that equals one if the investor trades stocks at least three days a week, or more often. Respondents are also asked if they bought and sold the same stock within a single day, which we recode into the indicator variable Day trading. ${ }^{5}$ We also ask respondents how many different individual stocks they hold in their portfolio, as a measure of diversification. Finally, investors are asked if they traded or invested in derivatives and leveraged products during the last 12 months.

Summary statistics of the trading variables are shown in Panel $\mathrm{C}$ of Table 1 . Investors in both samples trade stocks quite infrequently, with the most common answer being "1-10 times per year". Only $9 \%$ of the investors in the AFM panel trade stocks at least three times a week, versus a mere $2 \%$ of the DHS investors. The prevalence of day trading is around $20 \%$ in both samples. Hence, only a minority of the direct investors in the Dutch population trade stocks frequently. AFM investors tend to trade somewhat more actively, and hold more stocks in their portfolio relative to the DHS sample. ${ }^{6}$ Trading in derivatives and leveraged products is also rare in the DHS sample ( $11 \%$ and $4 \%$, respectively), but slightly more common in the AFM sample (28\% and $12 \%)$.

Finally, Panel $\mathrm{C}$ of Table 1 also shows descriptive statistics of our three measures of the investor's financial situation, defined in Appendix A. Most investors experience no difficulties making ends meet and have few financial problems. Only $15 \%$ of the investors experienced at least one financial problem during the last 12 months, such as receiving a letter from a debt collecting agency, or failing to pay the rent or mortgage on time. There are no significant differences in the mean values of the financial situation variables between the two samples.

\section{Results}

\subsection{Prevalence of compulsive gambling in the financial markets}

As shown in Panel A of Table 2, the typical Dutch investor displays almost no symptoms of compulsive gambling in the financial markets: $53 \%$ has no symptoms at all, while the average number of symptoms is about 1. However, still, 5.7\% (DHS) and 3.9\% (AFM) of the investors in both samples can be classified as potential compulsive gamblers in the financial markets, or trading addicts, because they display four or more DSM-5 symptoms. There is no significant difference in the proportion of trading addicts between the DHS and the AFM samples. Overall, $4.4 \%$ of the investors in the combined sample, or 1 out of 23 investors, is classified as a potential trading addict based on their responses, with a $95 \%$ confidence interval of $[2.5 \%, 7.0 \%] .^{7}$

\footnotetext{
5 Barber et al. (2014) find that day trading accounts for more than $20 \%$ of the total trading volume in Taiwan, but the vast majority of day traders lose money.

${ }^{6}$ The median number of different individual stocks owned is four in the DHS and six in the AFM sample.

${ }^{7}$ For the $5.7 \%$ estimate in the DHS the 95\% confidence interval is [2.1\%, $11.9 \%$, and for the $3.9 \%$ in AFM it is [1.9\%, $7.0 \%]$.
} 
Table 1

Summary statistics of the investor datasets.

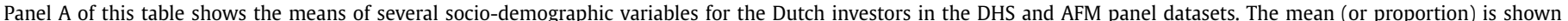

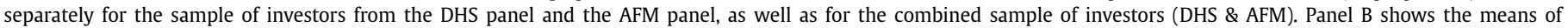

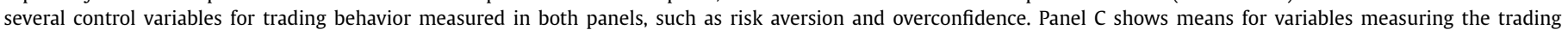

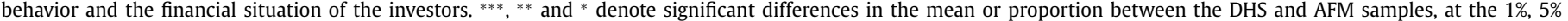
and $10 \%$ level.

\begin{tabular}{|c|c|c|c|}
\hline Panel A: Demographics & $\begin{array}{l}\text { Combined Sample } \\
\text { Mean }\end{array}$ & $\begin{array}{l}\text { DHS Sample } \\
\text { Mean }\end{array}$ & $\begin{array}{l}\text { AFM Sample } \\
\text { Mean }\end{array}$ \\
\hline Age in years & 60.8 & 59.0 & 61.5 \\
\hline Male & $92.9 \%$ & $90.6 \%$ & $93.8 \%$ \\
\hline Single & $21.7 \%$ & $27.4 \%$ & $19.3 \% *$ \\
\hline Low education & $6.4 \%$ & $11.3 \%$ & $4.3 \% * *$ \\
\hline High school education & $20.6 \%$ & $24.5 \%$ & $18.9 \%$ \\
\hline Bachelor education & $42.5 \%$ & $35.8 \%$ & $45.3 \% *$ \\
\hline Master education & $30.6 \%$ & $28.3 \%$ & $31.5 \%$ \\
\hline Low income $(<39 \mathrm{k}$ euro $)$ & $20.0 \%$ & $25.5 \%$ & $17.7 \% *$ \\
\hline Medium income ( $39 \mathrm{k}$ to $78 \mathrm{k}$ euro) & $40.3 \%$ & $54.7 \%$ & $34.3 \% * * *$ \\
\hline High income ( $>78 \mathrm{k}$ euro) & $31.1 \%$ & $19.8 \%$ & $35.8 \% * * *$ \\
\hline Low wealth $(<50$ k euro $)$ & $23.1 \%$ & $34.9 \%$ & $18.1 \%$ *** \\
\hline Medium wealth (50k to $150 \mathrm{k}$ euro) & $23.3 \%$ & $31.1 \%$ & $20.1 \% * *$ \\
\hline High wealth ( $>150$ k euro) & $43.3 \%$ & $33.0 \%$ & $47.6 \% * *$ \\
\hline Low stock trading experience ( $<1$ year) & $2.1 \%$ & $1.0 \%$ & $2.6 \%$ \\
\hline Medium stock trading exp. (1-5 years) & $8.7 \%$ & $14.0 \%$ & $6.4 \% * *$ \\
\hline High stock trading experience ( $>5$ years) & $89.2 \%$ & $85.0 \%$ & $91.0 \%$ \\
\hline Regular employment & $38.1 \%$ & $46.2 \%$ & $34.6 \% * *$ \\
\hline Business owner & $14.7 \%$ & $8.5 \%$ & $17.3 \% * *$ \\
\hline Retired & $41.1 \%$ & $39.6 \%$ & $41.7 \%$ \\
\hline Unemployed/disabled/other dummy & $6.1 \%$ & $5.7 \%$ & $6.3 \%$ \\
\hline Has access to financial advisor & $22.5 \%$ & $17.9 \%$ & $24.3 \%$ \\
\hline Observations & 365 & 106 & 259 \\
\hline \multicolumn{4}{|l|}{ Panel B: Control variables } \\
\hline Risk tolerance scale from 1 to 10 & 5.92 & 5.53 & $6.09^{* *}$ \\
\hline Financial literacy score ( $0-3$ correct) & 2.81 & 2.82 & 2.80 \\
\hline Self-assessed investment skill $1-5$ ( $1=$ Much worse than average, $\ldots, 4=$ Better, $5=$ Much better $)$ & 2.93 & 2.80 & $2.98^{* *}$ \\
\hline $\begin{array}{l}\text { Overconfidence better-than-average (\% who think they are better or just as good, but financial } \\
\text { literacy below avg.) }\end{array}$ & $11.5 \%$ & $9.4 \%$ & $12.4 \%$ \\
\hline \multicolumn{4}{|l|}{ Panel C: Dependent variables } \\
\hline Stock trading frequency, scale $1-5(1=\mathrm{I}$ barely trade, $\ldots, 5=$ almost every day $)$ & 2.28 & 1.88 & $2.46^{* * *}$ \\
\hline (1) I barely trade & $17.7 \%$ & $29.0 \%$ & $12.8 \% * * *$ \\
\hline (2) $1-10$ times per year & $46.7 \%$ & $56.0 \%$ & $42.7 \% * *$ \\
\hline (3) 1-10 times per month & $28.7 \%$ & $13.0 \%$ & $35.5 \% * * *$ \\
\hline (4) 3-4 times per week & $3.3 \%$ & $2.0 \%$ & $3.9 \%$ \\
\hline (5) Almost every day & $3.6 \%$ & $0.0 \%$ & $5.1 \% * *$ \\
\hline High stock trading frequency (at least 3 times a week or more) & $6.9 \%$ & $2.0 \%$ & $9.0 \% * *$ \\
\hline Day trading stocks & $21.0 \%$ & $19.0 \%$ & $21.8 \%$ \\
\hline Number of stocks & 8.5 & 5.1 & $10.0^{* * *}$ \\
\hline Investing in derivatives & $23.0 \%$ & $11.3 \%$ & $27.8 \% * * *$ \\
\hline Investing in leveraged products & $9.6 \%$ & $3.8 \%$ & $12.0 \% * *$ \\
\hline Making ends meet scale $1-5(1=$ very easy, $\ldots, 5=$ very difficult $)$ & 1.79 & 1.98 & $1.72^{* * *}$ \\
\hline Financial situation scale $1-5$ ( $1=$ money left over, $\ldots, 5=$ debt increasing $)$ & 1.92 & 2.01 & 1.89 \\
\hline Financial situation deteriorating dummy & $9.6 \%$ & $11.0 \%$ & $9.1 \%$ \\
\hline Number of financial problems $(0-8)$ & 0.30 & 0.26 & 0.32 \\
\hline Has at least one serious financial problem & $14.9 \%$ & $15.2 \%$ & $14.8 \%$ \\
\hline Observations & 365 & 106 & 259 \\
\hline
\end{tabular}

${ }^{* * *},{ }^{* *}$ and ${ }^{*}$ denote significant differences in the mean or proportion between the AFM and DHS samples, at the $1 \%, 5 \%$ and $10 \%$ level.

To put this result in perspective, a meta-study by Stucki and Rihs-Middel (2007) estimates the rate of gambling disorder in the global population as $1.9 \%$, considering conventional ways of gambling (casinos, slot machines, sports betting, etc.). Two large survey studies estimate the rate of compulsive gambling in the Dutch general population as only $0.2 \%$ (Goudriaan, 2014). One reason that the compulsive gambling rate is considerably higher at $4.4 \%$ in our sample of Dutch investors is that we consider investors who directly trade stocks and financial products themselves, already implying some exposure to financial gains and losses that some may find attractive from a gambling perspective.

We note that our estimate of $4.4 \%$ potential compulsive gamblers among Dutch direct investors probably understates the actual number of trading addicts in the financial markets. The reason is that more investors will likely try to conceal or mask their gambling problems by giving false survey responses, compared to respondents incorrectly declaring more symptoms than they actually have. It is more usual for people to conceal problematic behavior until it starts to affect others surrounding them. Hence, our estimate can be considered as a lower bound for the real occurrence of compulsive gambling among Dutch retail investors. ${ }^{8}$

Table 2 in addition shows that apart from the $4.4 \%$ of investors classified as possible trading addicts because they display four

\footnotetext{
${ }^{8}$ An interesting approach for future research is to apply a list randomization technique, where sensitive questions are hidden in a block of neutral questions and the respondent only indicates how many of the statements in a block are correct. This approach can improve estimates of prevalence rates for sensitive behaviours such as compulsive gambling. A drawback is that it does not identify exactly which respondents in the sample are a compulsive gambler.
} 
Table 2

Compulsive gambling in the financial markets and gambling motives.

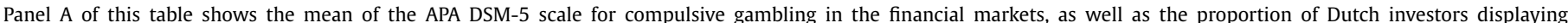

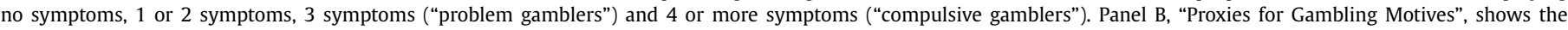

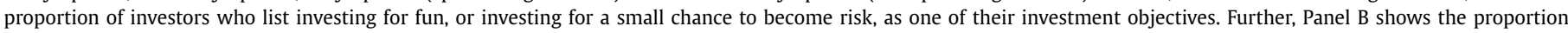

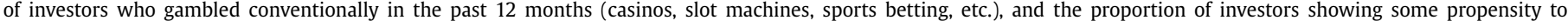

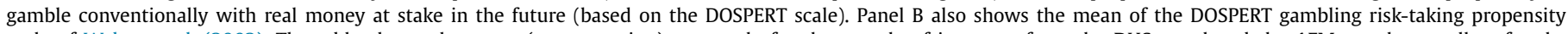

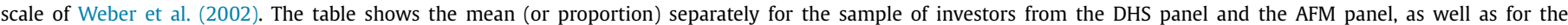

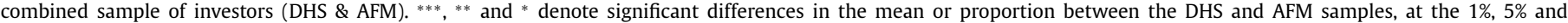
$10 \%$ level.

\begin{tabular}{|c|c|c|c|}
\hline Panel A: Compulsive gambling symptoms & $\begin{array}{l}\text { Combined Sample } \\
\text { Mean }\end{array}$ & $\begin{array}{l}\text { DHS Sample } \\
\text { Mean }\end{array}$ & $\begin{array}{l}\text { AFM Sample } \\
\text { Mean }\end{array}$ \\
\hline \multicolumn{4}{|l|}{ APA DSM-5 compulsive gambling criteria } \\
\hline Number of compulsive gambling symptoms (0-9 symptoms) & 0.89 & 0.71 & $0.96^{*}$ \\
\hline No symptoms (\%) (Has no symptoms) & $53.4 \%$ & $65.1 \%$ & $48.6 \% * * *$ \\
\hline Some symptoms (\%) (Has 1 or 2 symptoms) & $38.6 \%$ & $28.3 \%$ & $42.9 \% * * *$ \\
\hline Problem gamblers (\%) (Has exactly 3 symptoms) & $3.6 \%$ & $0.9 \%$ & $4.6 \% *$ \\
\hline Compulsive gamblers (\%) (Has 4 or more symptoms) & $4.4 \%$ & $5.7 \%$ & $3.9 \%$ \\
\hline Observations & 365 & 106 & 259 \\
\hline \multicolumn{4}{|l|}{ Panel B: Proxies for gambling motives } \\
\hline Sensation seeking motive ("Investing for fun or the challenge") & $44.7 \%$ & $48.1 \%$ & $43.2 \%$ \\
\hline Wealth aspiration motive ("Investing for a small chance to get rich") & $13.4 \%$ & $10.4 \%$ & $14.7 \%$ \\
\hline Past gamblers (Gambled conventionally in the last year) & $10.7 \%$ & $14.2 \%$ & $9.3 \%$ \\
\hline Risk-taking gamblers (DOSPERT Gambling propensity > 1) & $8.2 \%$ & $9.4 \%$ & $7.7 \%$ \\
\hline DOSPERT gambling risk-taking scale (1-5) & 1.14 & 1.17 & 1.13 \\
\hline
\end{tabular}

or more DSM-5 symptoms, there is another $3.6 \%$ with three symptoms that are potential "problem gamblers", which a less severe form of gambling disorder (Volberg, 2001). Similar to our study, Kamolsareeratana and Kouwenberg (2019) fielded a survey among Thai investors and found $4.9 \%$ compulsive gamblers and 9.5\% problem gamblers, respectively. Youn et al. (2016) report that $21.5 \%$ of a sample of Korean investors meet the criteria for trading addiction, a substantially higher rate than we find in the Netherlands, but the prevalence rate of conventional gambling addictions in Korea is also about two to three times higher than in most other countries (at 5.1\%). ${ }^{9}$ Another key difference is that both studies used a convenience sample of investors, while our sample is representative for individual investors in the Netherlands.

\subsection{Summary statistics of gambling motives measures}

Panel B of Table 2 reports descriptive statistics of our measures for gambling motives. About $45 \%$ of the investors in both samples mention "investing for the fun or the challenge" as one of their investment goals, indicating that entertainment and sensation seeking are common motives among Dutch individual investors. On the other hand, only 10\% (DHS) to 15\% (AFM) indicate that they invest for a small chance to get rich.

Further, only about $9 \%$ (AFM) to $14 \%$ (DHS) of the investors participated in conventional gambling activities in the last 12 months. The mean of the DOSPERT scale is also close to 1 (="Very Unlikely"), confirming that gambling propensity among Dutch investors is low. Only about $8 \%$ of the investors can be classified as risk-taking gamblers based on the DOSPERT-scale, indicating that they may gamble with at least 100 euro of real money in casinos, on card games, on slot machines, or in sports betting.

We conclude that the number of Dutch investors displaying direct and indirect gambling motives is substantially higher than the number of potential trading addicts. This is important, as the compulsive gambling screen should be exclusive and only isolating more extreme cases of gambling in the stock market to be useful. In the remainder of the paper, we will use the direct and indirect proxies for gambling motives to further compare and contrast with the small group of compulsive gamblers to help validate

\footnotetext{
${ }^{9}$ The Korean National Gambling Control Commission (2016).
}

the trading addiction scale. Finally, we note that there are no significant differences in gambling motives between the AFM and DHS samples.

\subsection{Profile of compulsive gamblers in the financial markets}

Table 3 compares the socio-demographic profile of compulsive gamblers in the financial markets (Column 1) to other individual investors (Column 2), testing for significant differences (Column 3 ). Trading addicts have lower education, lower income, and less wealth, which agrees with the typical profile of gambling addicts in other domains, who tend to have lower socioeconomic status (Welte et al., 2015). Trading addicts also are more likely to engage in conventional gambling activities (37.5\%), such as gambling in casinos and sports betting. However, we also note that there is no perfect overlap between trading addiction and participating in conventional gambling activities, as 8 out of the 16 (50\%) potential trading addicts indicate not having gambled conventionally during the last 12 months and also show no propensity to do so in the future on the DOSPERT scale.

\subsection{Relation with frequent stock trading}

We now test whether compulsive gambling is related to active and speculative stock trading behaviors by individual investors, to validate the scale. We combine both investor samples, DHS and AFM, given their similarity in terms of age, gender, trading experience, access to financial advice, and gambling motives. Moreover, this assures us of having a sufficient number of observations to estimate regression models for trading behavior, while we control for any difference in the samples by including a dummy for AFM respondents.

We note that some of the DSM-5 diagnostic criteria in Appendix A refer to difficulties with reducing or quitting trading financial products, which naturally should create a positive relation with a higher stock trading frequency and day trading. The purpose of our tests in this section is to validate the trading addiction scale by checking if it relates to trading behavior in the expected way. A significant positive relation is not guaranteed, however, as investors could try to conceal their addiction problems, or give incorrect answers to the survey questions. 
Table 3

Profile of compulsive gamblers in the Dutch financial markets.

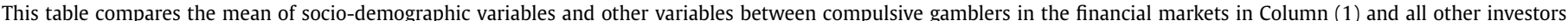

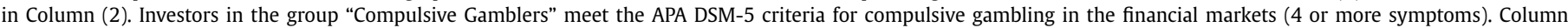

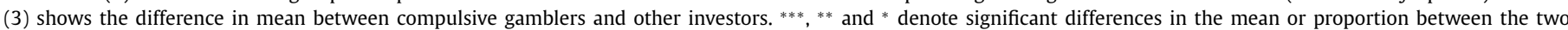
groups, at the $1 \%, 5 \%$ and $10 \%$ level.

\begin{tabular}{|c|c|c|c|}
\hline & $\begin{array}{l}\text { (1) } \\
\text { Compulsive Gamblers } \\
\text { Mean }\end{array}$ & $\begin{array}{l}(2) \\
\text { Other Investors } \\
\text { Mean }\end{array}$ & $\begin{array}{l}(3) \\
\text { Difference (1)-(2) } \\
\text { Mean }\end{array}$ \\
\hline \multicolumn{4}{|l|}{ Demographics } \\
\hline Age in years & 59.6 & 60.8 & -1.2 \\
\hline Male & $100.0 \%$ & $92.6 \%$ & $7.4 \%$ \\
\hline Single & $25.0 \%$ & $21.5 \%$ & $3.5 \%$ \\
\hline Low education & $18.8 \%$ & $5.8 \%$ & $12.9 \% * *$ \\
\hline High school education & $25.0 \%$ & $20.3 \%$ & $4.7 \%$ \\
\hline Bachelor education & $56.3 \%$ & $41.9 \%$ & $14.4 \%$ \\
\hline Master education & $0.0 \%$ & $32.0 \%$ & $-32.0 \% * * *$ \\
\hline Low income ( $<39 \mathrm{k}$ euro $)$ & $31.3 \%$ & $19.5 \%$ & $11.8 \%$ \\
\hline Medium income ( $39 \mathrm{k}$ to $78 \mathrm{k}$ euro) & $62.5 \%$ & $39.2 \%$ & $23.3 \% *$ \\
\hline High income ( $>78 \mathrm{k}$ euro) & $0.0 \%$ & $32.6 \%$ & $-32.6 \% * * *$ \\
\hline Low wealth ( $<50 \mathrm{k}$ euro $)$ & $43.8 \%$ & $22.1 \%$ & $21.7 \% * *$ \\
\hline Medium wealth (50k to $150 \mathrm{k}$ euro) & $31.3 \%$ & $23.0 \%$ & $8.3 \%$ \\
\hline High wealth ( $>150 \mathrm{k}$ euro $)$ & $18.8 \%$ & $44.5 \%$ & $-25.7 \% * *$ \\
\hline Has access to financial advisor & $25.0 \%$ & $22.3 \%$ & $2.7 \%$ \\
\hline \multicolumn{4}{|l|}{ Controls } \\
\hline Risk tolerance scale from 1 to 10 & 6.56 & 5.89 & $0.67 *$ \\
\hline Financial literacy score ( $0-3$ correct) & 2.81 & 2.81 & 0.00 \\
\hline Self-assessed investment skill (1-5) & 2.50 & 2.95 & $-0.45^{* *}$ \\
\hline $\begin{array}{l}\text { Overconfidence better-than-average (\% who think they are better or just as good, but } \\
\text { financial literacy below avg.) }\end{array}$ & $6.3 \%$ & $11.7 \%$ & $-5.5 \%$ \\
\hline \multicolumn{4}{|l|}{ Gambling motives } \\
\hline Sensation seeking motive ("Investing for fun or the challenge") & $56.3 \%$ & $44.1 \%$ & $12.1 \%$ \\
\hline Wealth aspiration motive ("Investing for a small chance to get rich") & $18.8 \%$ & $13.2 \%$ & $5.6 \%$ \\
\hline Past gamblers (Gambled conventionally in the last year) & $37.5 \%$ & $9.5 \%$ & $28.0 \% * * *$ \\
\hline Risk-taking gamblers (DOSPERT Gambling propensity > 1) & $37.5 \%$ & $6.9 \%$ & $30.6 \% * * *$ \\
\hline DOSPERT gambling scale ( 1 to 5 ) & 1.61 & 1.12 & $0.49^{* *}$ \\
\hline Observations & 16 & 349 & \\
\hline
\end{tabular}

\section{Table 4}

Trading behavior and financial situation of compulsive gamblers versus other investor groups.

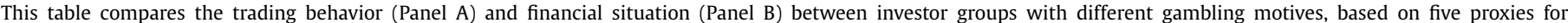

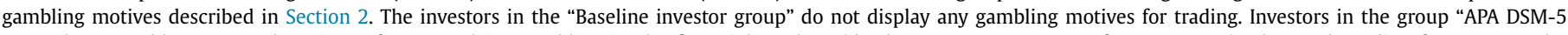

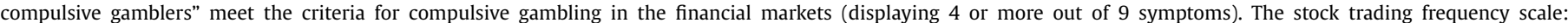

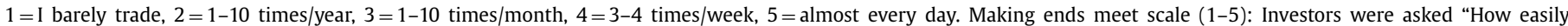

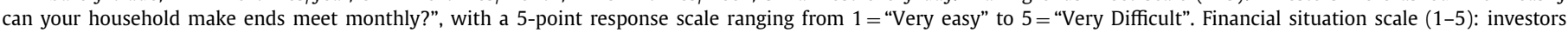

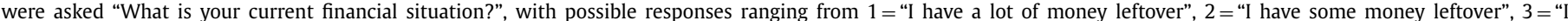

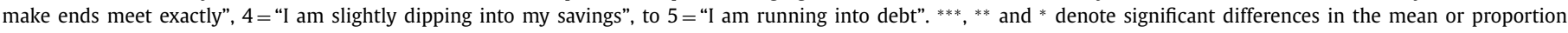
compared to the baseline group, at the $1 \%, 5 \%$ and $10 \%$ level.

\begin{tabular}{|c|c|c|c|c|c|c|}
\hline Panel A: Trading behavior & $\begin{array}{l}\text { Baseline } \\
\text { investor } \\
\text { group }\end{array}$ & $\begin{array}{l}\text { APA DSM-5 } \\
\text { compulsive } \\
\text { gamblers }\end{array}$ & $\begin{array}{l}\text { Invest for fun } \\
\text { or the } \\
\text { challenge }\end{array}$ & $\begin{array}{l}\text { Invest for a } \\
\text { chance to } \\
\text { become rich }\end{array}$ & $\begin{array}{l}\text { Gambled in } \\
\text { the last } 12 \\
\text { months }\end{array}$ & $\begin{array}{l}\text { DOSPERT } \\
\text { gambling } \\
\text { propensity }\end{array}$ \\
\hline Stock trading frequency scale $(1-5)$ & 2.11 & $2.88^{* * *}$ & $2.41^{* * * *}$ & $2.51^{* * * *}$ & $2.53^{* *}$ & $2.64^{* * *}$ \\
\hline High trading frequency dummy (\%) & $5.5 \%$ & $18.8 \% * *$ & $6.5 \%$ & $7.3 \%$ & $11.1 \%$ & $14.3 \% *$ \\
\hline Day trading stocks $(\%)$ & $13.1 \%$ & $62.5 \% * * *$ & $24.2 \% * *$ & $31.7 \% * * *$ & $33.3 \% * * *$ & $46.4 \% * * *$ \\
\hline Invests in derivatives (\%) & $16.0 \%$ & $37.5 \% * *$ & $30.1 \% * * *$ & $28.6 \% *$ & $33.3 \% * *$ & $26.7 \%$ \\
\hline Invests in leveraged products (\%) & $6.8 \%$ & $18.8 \% *$ & $12.3 \%^{*}$ & $10.2 \%$ & $23.1 \% * * *$ & $23.3 \% * * *$ \\
\hline Number of stocks & 8.10 & 8.38 & 9.44 & 7.69 & 7.56 & 7.50 \\
\hline Observations (N) & 162 & 16 & 163 & 49 & 39 & 30 \\
\hline \multicolumn{7}{|l|}{ Panel B: Financial situation } \\
\hline Making ends meet scale (1-5) & 1.79 & $2.47^{* * *}$ & 1.75 & 1.73 & 1.95 & $2.23^{* * *}$ \\
\hline Financial situation scale (1-5) & 1.94 & $2.80^{* * *}$ & 1.84 & 1.80 & $2.34^{* *}$ & $2.41^{* *}$ \\
\hline Number of financial problems (1-8) & 0.24 & $0.94^{*}$ & 0.30 & 0.33 & $0.79 * *$ & $0.69 *$ \\
\hline Making debt or using savings (\%) & $10.9 \%$ & $33.3 \% * *$ & $8.2 \%$ & $6.1 \%$ & $21.1 \% *$ & $20.7 \%$ \\
\hline At least one financial problem (\%) & $14.3 \%$ & $31.3 \% *$ & $14.2 \%$ & $12.2 \%$ & $34.2 \% * * *$ & $24.1 \%$ \\
\hline
\end{tabular}

Table 4 and Fig. 2 compare the trading behavior of investors with different gambling motives, for the combined total sample of 365 investors. The baseline investor group in the first column of Table 4 consists of respondents who indicate to have no gambling motives at all. On average, most investors in the baseline group do not trade stocks actively: just 1-10 times per year. Only 6\% of the investors in the baseline group have a high stock trading frequency, and 13\% day-trade stocks. The second column of Table 4 summarizes the trading behavior of compulsive gamblers, the small group of 16 investors who display four or more DSM-5 symptoms of trading addiction. The compulsive gamblers have a significantly higher stock trading frequency on average compared 


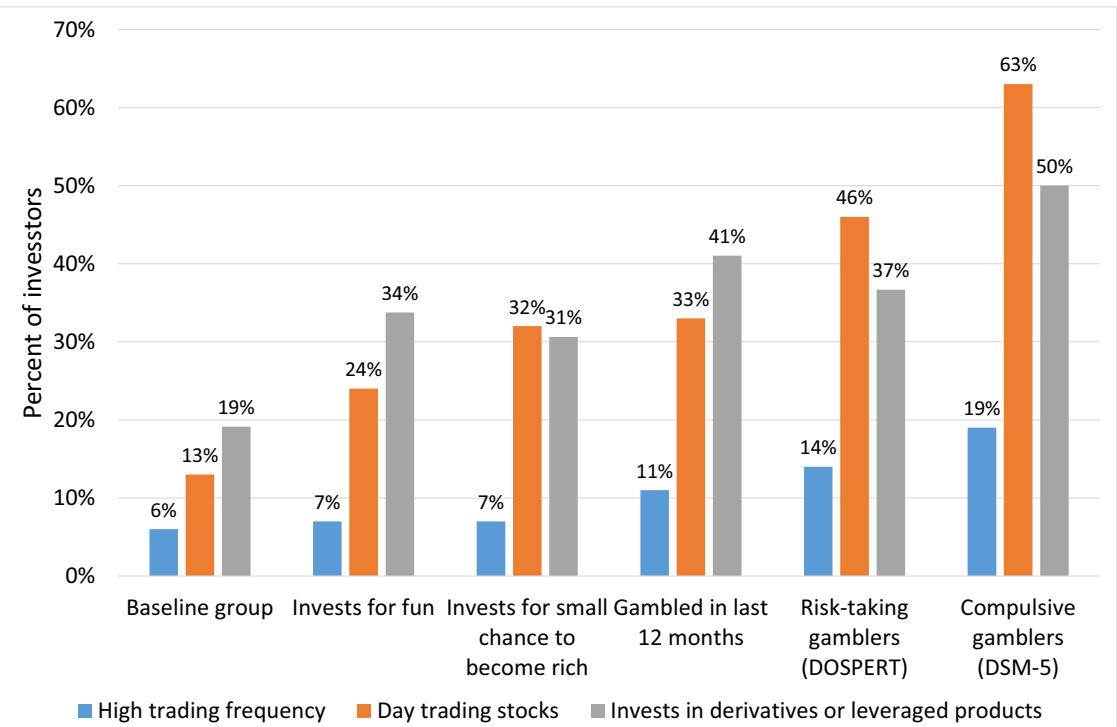

Fig. 2. Trading behavior of investors with gambling motives.

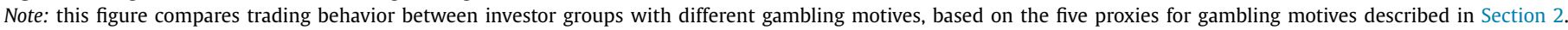

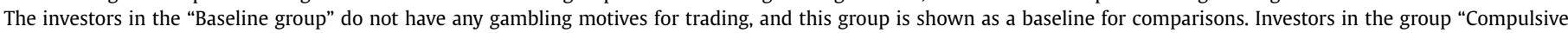

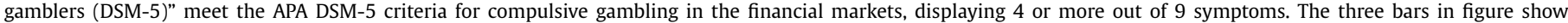

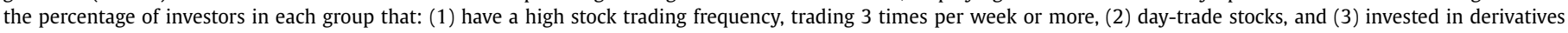
or leveraged products during the last 12 months.

to the baseline group, and one out of five (19\%) trades at least three times per week or more. Further, the day-trading rate of $63 \%$ among compulsive gamblers is about five times higher than among the baseline group (13\%).

As a contrast, we also examine trading behavior in four groups of investors based on the direct and indirect proxies for gambling motives. Among sensation seekers, investors who trade for fun, and wealth aspirers, who trade to become rich, the average trading frequency and the tendency to day-trade (24-32\%) are significantly higher than in the baseline group. However, there is no difference in the prevalence of a high trading frequency (only 7\%) in these two groups compared to the baseline (5.5\%).

We also form two groups based on the indirect proxies for gambling motives, based on their conventional gambling activities. The first group consists of investors who participated in conventional gambling activities in the past twelve months (excluding lotteries). The second group exhibit some propensity to gamble with real money on the DOSPERT-scale. Table 4 shows that both groups of conventional gamblers are about three times more likely to day-trade stocks and twice as likely to have a high stock trading frequency, compared to the baseline group. For example, in the group of investors who show some gambling propensity based on the DOSPERT-scale, about 50\% day-trade stocks and $14 \%$ have a high stock trading frequency.

Overall, the results in Table 4 show that active trading is more common among compulsive gamblers in the financial markets, and among investors who also gamble conventionally. ${ }^{10}$ The compulsive gamblers have the highest average trading frequency, and the highest rate of day-trading. Fig. 2 illustrates this pattern.

Next, we estimate logit regression models for stock trading to control for other explanations such as overconfidence, risk tolerance, financial literacy, as well as socio-demographic variables. The

\footnotetext{
10 Table 4 shows no significant difference in the mean number of stocks held by the investor groups. In the DHS sample we also have data on the portfolio fraction of financial assets invested in individual stocks, a better proxy for portfolio diversification, and using this variable there are also no significant differences between groups.
}

models include measures for risk tolerance (Dohmen et al., 2011), financial literacy (Lusardi and Mitchell, 2007) and the better-thanaverage form of overconfidence. Further, we include controls for age, gender, marital status, education level, income, wealth, stock trading experience, and a dummy variable to account for any differences in trading behavior between the AFM and DHS samples.

The results in Table 5 show that compulsive gamblers are more likely to have a high trading frequency and are more likely to day-trade. The effect size is large: compulsive gamblers are approximately three times more likely to have a high stock trading frequency and to engage in day-trading. As a robustness check, we have also estimated the regressions in Table 5 with the number of compulsive gambling symptoms (ranging from 0 to 9 ) as the independent variable, which gives the same results. Table 5 also shows that the other proxies for gambling motives, such investing for fun, aspiring for riches or being a conventional gambler, mostly do not have a significant relation with active stock trading, after controlling for compulsive gambling and other variables. The only exception is that investors who trade for fun tend to have a higher stock trading frequency in Column (2) of Table 5.

These results verify that the compulsive gambling screen is effective at isolating a small group of investors with relatively active trading behavior, who are potentially driven by a compulsive urge to gamble. Among the control variables, we find that investors with higher risk tolerance and lower financial literacy are more likely to day-trade in Table 5 (Column 3). Investors who rate their own investment skills more favorably and those with higher risk tolerance tend to trade stocks more frequently (Column 2).

\subsection{Derivatives and leveraged products}

We now test whether investors who display compulsive gambling symptoms are more likely to invest in derivatives and leveraged products. Both derivatives and leveraged products are attractive from a gambling perspective, as they allow retail investors to achieve highly skewed and levered payoffs. However, due to their complex nature and low liquidity, these products are usually relatively expensive to trade and carry high fees, increasing the 
Table 5

Regression models for trading behavior.

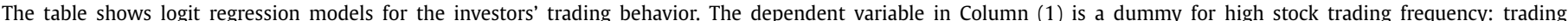

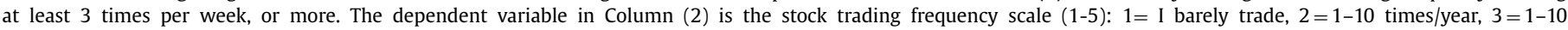

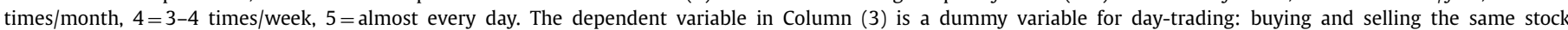

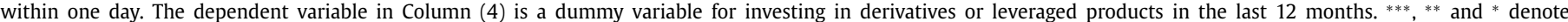
significance at $1 \%, 5 \%$ and $10 \%$ level.

\begin{tabular}{|c|c|c|c|c|}
\hline & $\begin{array}{l}\text { (1) } \\
\text { High trading } \\
\text { frequency dummy }\end{array}$ & $\begin{array}{l}(2) \\
\text { Trading frequency } \\
\text { scale }\end{array}$ & $\begin{array}{l}\text { (3) } \\
\text { Day trading } \\
\text { dummy }\end{array}$ & $\begin{array}{l}\text { (4) } \\
\text { Investing in derivatives } \\
\text { or lev. products }\end{array}$ \\
\hline APA DSM-5 compulsive gamblers dummy & $1.90^{* * * *}$ & $1.39^{* *}$ & $1.94^{* *}$ & $1.38^{* *}$ \\
\hline DOSPERT gambling propensity dummy & 1.18 & 0.72 & $1.00^{*}$ & 0.22 \\
\hline Gambled last 12 months dummy & 0.26 & 0.15 & -0.02 & 0.54 \\
\hline Investing for chance to become rich dummy & 0.04 & 0.37 & 0.76 & -0.00 \\
\hline Investing for fun or the challenge dummy & -0.12 & $0.52^{* *}$ & 0.21 & $0.52^{*}$ \\
\hline Risk tolerance & 0.14 & $0.24^{* * *}$ & $0.31^{* * *}$ & $0.15^{*}$ \\
\hline Financial literacy & $-1.18^{*}$ & -0.01 & $-0.79 * *$ & 0.79 \\
\hline Self-assessed investment skill & 0.56 & $0.44^{* * *}$ & 0.13 & 0.26 \\
\hline Overconfidence better than average & -0.89 & -0.08 & -0.01 & 0.64 \\
\hline High trading experience ( $>5$ years) & -0.48 & -0.60 & 0.19 & $1.38^{*}$ \\
\hline Age in years & $0.04^{*}$ & $0.02 *$ & 0.01 & 0.00 \\
\hline Male & -0.17 & 0.53 & $-1.23^{* *}$ & -0.10 \\
\hline Single & 0.63 & -0.01 & $-1.12^{* *}$ & 0.14 \\
\hline Master degree & 0.09 & 0.09 & 0.19 & -0.12 \\
\hline Low income $(<39 \mathrm{k}$ euro $)$ & -0.82 & -0.35 & 0.52 & 0.28 \\
\hline High income ( $>78 \mathrm{k}$ euro) & 0.40 & 0.30 & -0.05 & 0.45 \\
\hline Low wealth $(<50 \mathrm{k}$ euro $)$ & -0.19 & 0.07 & -0.08 & -0.21 \\
\hline High wealth (> 50k euro) & 0.48 & 0.16 & -0.24 & -0.05 \\
\hline DHS panel member & $-1.63^{* *}$ & $-1.28^{* * *}$ & -0.15 & $-1.13^{* * *}$ \\
\hline AFM respondent recruited by GfK & -0.51 & -0.26 & 0.06 & -0.51 \\
\hline Pseudo-R2 & 0.176 & 0.121 & 0.163 & 0.137 \\
\hline Observations & 328 & 328 & 328 & 328 \\
\hline
\end{tabular}

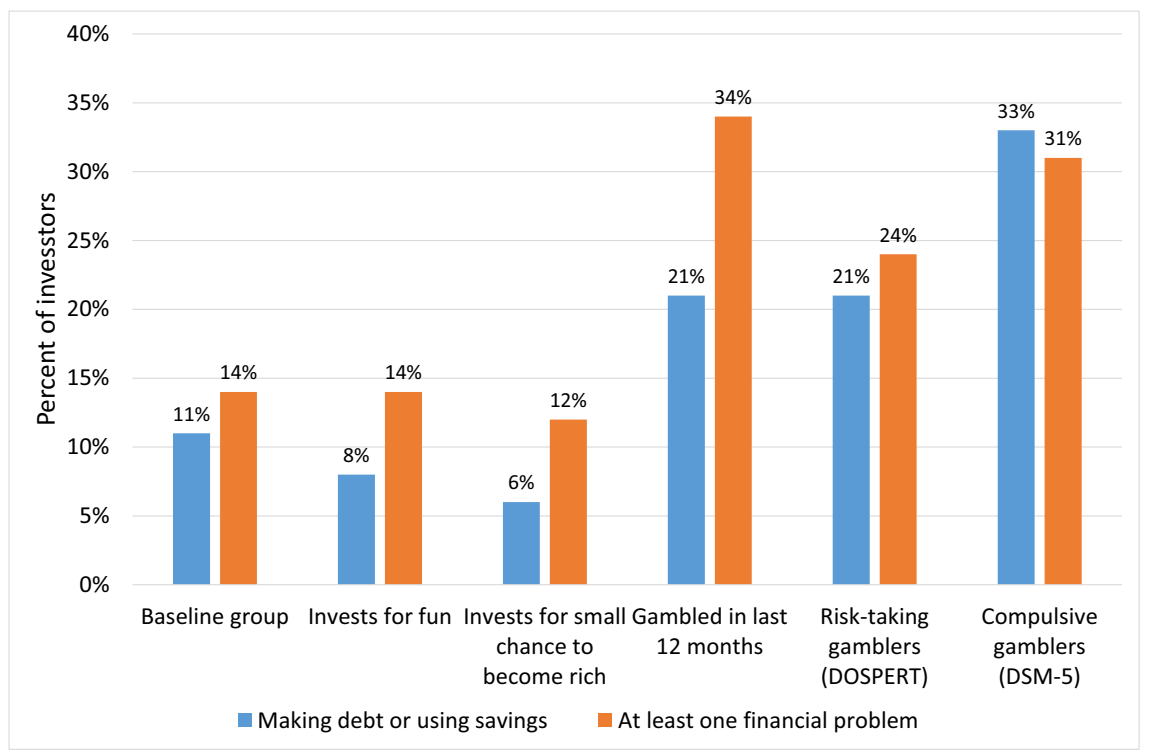

Fig. 3. Financial situation of investors with gambling motives

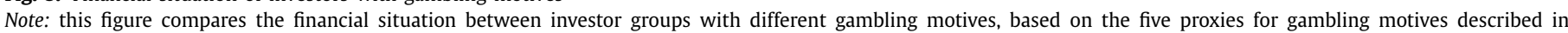

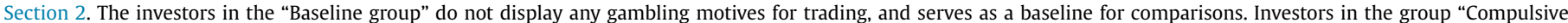

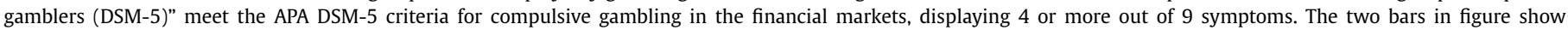

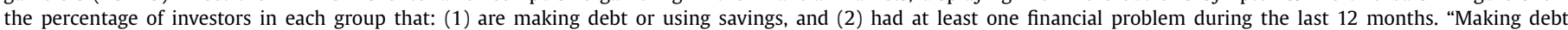

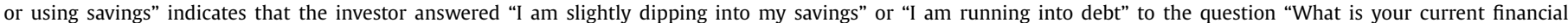

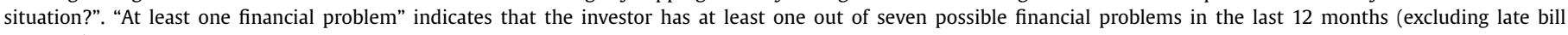
payment).

likelihood of poor returns. For example, Entrop et al. (2016) document that retail investors typically realize negative abnormal returns when investing in structured financial products. Further, Bauer et al. (2009) show that Dutch investors tend to suffer larger losses on their option investments than on their stock portfolios. Hence, similar to active stock trading, it is puzzling why individ- ual investors choose to invest in these products, and gambling motives may provide an explanation. ${ }^{11}$ With our data, we now

\footnotetext{
11 Bauer et al. (2009) argue that gambling and entertainment motives are the main drivers for option trading by Dutch retail investors. Related, Filippou et al (2018) show that there is a substitution effect between options and lottery stocks
} 
test whether compulsive gambling is a possible reason why some individual investors invest in options and leveraged products.

Panel B of Table 4 shows that investors with compulsive gambling symptoms are two times more likely to invest in derivatives (38\%), compared to investors without any gambling motives (16\%). Focusing on leveraged products, Table 4 shows that investors with compulsive gambling symptoms are about two times more likely to invest in these products (19\%), compared to the baseline group (7\%). Investors in the four other groups based on direct and indirect proxies for gambling motives also show significantly higher rates of investing in derivatives and leveraged products. Specifically, those who gambled conventionally in the last 12 months are more likely trade derivatives (33\%) and leveraged products (23\%), suggesting that some investors use these financial products as a substitute for conventional gambling.

Table 5 shows estimates for a logistic regression model explaining whether investors traded derivatives or leveraged products during the past twelve months, while controlling for overconfidence, risk tolerance, financial literacy, and socio-demographic variables. In line with the results for stock trading, compulsive gamblers are more likely to invest in derivatives and leveraged products. The other proxies for gambling motives do not have a significant relation with investing in these products, after compulsive gambling and other variables have been controlled for. Only investing for fun has a positive relation with trading derivatives and leveraged products at the $10 \%$ level. Other variables that show a marginally significant relation with investing in derivatives and leveraged products are higher risk tolerance and trading experience.

\subsection{Relation with financial situation}

In the previous sections, we found that compulsive gambling is associated with more active and speculative trading by individual investors, beyond known factors like overconfidence, risk tolerance and financial literacy. As a further validation of the compulsive trading scale, we now analyze how the DSM-5 screen relates to the financial situation of the investors. The gambling literature shows that compulsive gambling is typically associated with financial problems, debt and higher rates of personal bankruptcy (Ladouceur et al., 1994; Gerstein et al., 1999). We note upfront that we cannot verify the causal direction of these relations, as it also plausible that investors with financial problems and lower income are more attracted to gambling.

We use three measures for the investor's financial situation. First, our survey directly asked the respondents about their Financial situation and their ability to Make ends meet, using 5-point response scales (see Appendix A). The survey also asked if the respondent experienced eight common financial problems in the past year, such as receiving letters from a debt collection agency, or being in arrears on mortgage or rent payments. We obtained these questions about eight types of financial problems from the National Institute of Household Budget Research (NIBUD), which is an agency that studies household finances in The Netherlands. We use the total number of affirmative answers, ranging from 0 to 8 , as a proxy for financial problems (Number of financial problems). Finally, we construct two dummy variables, one for investors that indicate to accumulate debt or have to use their savings to make ends meet, and one for investors with at least one financial problem excluding late bill payment (which arises frequently because people forget to pay).

Panel $B$ in Table 4 and Fig. 3 show the average financial situation for the baseline group without gambling motives, the

for retail investors, with out-of-the-money options replacing lottery stocks when available. compulsive gamblers, and groups based on the proxies for gambling motives. Compulsive gamblers have significantly worse scores on all indicators of financial situation compared to the baseline investor group: they are three times more likely to accumulate debt or dip into their savings, and more than twice as likely to have experienced at least one financial problem in the last 12 months. A similar picture emerges for investors who gamble conventionally, although less extreme. Past gamblers and risk-taking gamblers are about twice as likely to accumulate debt or use their savings. On the other hand, investors who just trade for fun, or for a chance to get rich, have a financial situation similar to the baseline group (no significant difference).

Table 6 shows regression models for the three financial situation measures, including a full set of control variables. ${ }^{12}$ The results confirm that compulsive gamblers tend to be in significantly worse financial situation and face more financial problems, compared to other investors with a similar socio-demographic profile. ${ }^{13}$ Investors who gamble conventionally also report a worse financial situation. On the other hand, investing for fun and for a small chance to get rich are not associated with a worse financial situation and more financial problems, in line with the previous results for active and speculative trading behavior.

\section{Discussion and limitations}

As pointed out earlier, some of the DSM- 5 diagnostic criteria in Appendix A refer to difficulties with reducing or quitting trading financial products, which by definition should create a positive relation with more frequent stock trading. The purpose of our tests in Section 4 was to validate the trading addiction scale by checking if it relates to trading frequency in the expected way. A positive relation was not guaranteed, as compulsive traders can try conceal their problems by giving false answers, and in general people may give incorrect answers to survey questions. Our results in Section 4 thus suggests that untruthful or incorrect answers are not a major problem. In addition, one of the nine DSM-5 criteria refers to "You have to borrow money from family members or friends to cover the losses from trading in financial products", a question linked to the investor's financial situation. Again, we still test the relation between compulsive gambling and financial situation as a validation of the scale.

One limitation of our research is that with a cross-sectional dataset it is not possible to establish the direction of causality, despite the inclusion of a wide variety of exogenous background characteristics in the regression models. This holds especially true for the relation between compulsive gambling in the stock market and the investor's financial situation. One way to interpret the results is that investors who gamble compulsive in the stock market end up in a relatively worse financial situation due to the costs and losses of their speculative trading strategies. Conversely, it is also conceivable that a relatively bad financial situation triggers individuals to gamble in financial markets in an attempt to catch up and quickly gain a large amount of wealth. Regardless of the exact direction of causality, either scenario raises concerns and warrants screening for compulsive gambling motives by brokers.

Another limitation is that trading behavior is self-reported in our survey data, while we do not have evidence from actual trading records. However, our survey data has also some advantages over trading records from brokerage accounts. Investors can have

\footnotetext{
12 Results are similar if we use the number of compulsive gambling symptoms (0-9) as independent variable.

13 Further, in results available on request we find that the compulsive gamblers in the DHS sample give a lower rating to their health condition than other investors. In general, DHS investors who display more compulsive gambling symptoms tend to report a lower health condition (correlation $r=0.23, p=0.020$ ).
} 
Table 6

Regression models for financial situation.

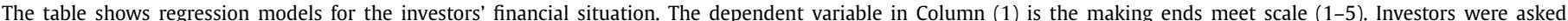

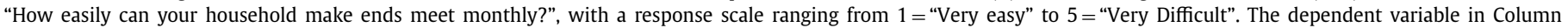

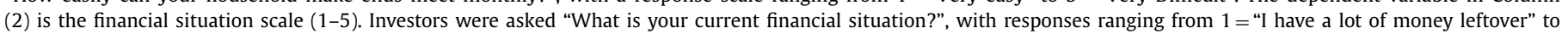

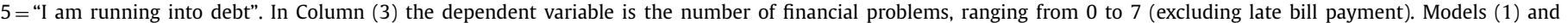
(2) are estimated with an ordered logit regression, and Model (3) is a Poisson count model.

***, ${ }^{* *}$ and $*$ denote significance at the $1 \%, 5 \%$ and $10 \%$ levels, respectively.

\begin{tabular}{|c|c|c|c|}
\hline & $\begin{array}{l}(1) \\
\text { Making ends meet } \\
\text { scale (1-5) }\end{array}$ & $\begin{array}{l}(2) \\
\text { Financial situation scale } \\
(1-5)\end{array}$ & $\begin{array}{l}\text { (3) } \\
\text { Number of financial } \\
\text { problems }\end{array}$ \\
\hline APA DSM-5 compulsive gamblers dummy & $1.27^{* * * *}$ & $1.44^{* * * *}$ & $0.97^{* *}$ \\
\hline DOSPERT gambling propensity dummy & $1.09^{* *}$ & 0.47 & 0.47 \\
\hline Gambled last 12 months dummy & 0.01 & $1.16^{* * *}$ & $0.57^{*}$ \\
\hline Investing for chance to become rich dummy & -0.09 & -0.27 & 0.02 \\
\hline Investing for fun or the challenge dummy & -0.29 & $-0.45^{*}$ & -0.31 \\
\hline Risk tolerance & -0.04 & -0.01 & 0.03 \\
\hline Financial literacy & $-0.83^{* *}$ & -0.07 & $-0.70^{* *}$ \\
\hline Self-assessed investment skill & -0.04 & $-0.23^{*}$ & $0.31^{*}$ \\
\hline Overconfidence better than average & -0.73 & -0.17 & $-0.87^{*}$ \\
\hline High trading experience ( $>5$ years) & -0.14 & $0.85^{* *}$ & 0.49 \\
\hline Age in years & 0.01 & $0.03^{* * *}$ & -0.02 \\
\hline Male & 0.13 & -0.12 & -0.19 \\
\hline Single & 0.13 & -0.01 & -0.31 \\
\hline Master degree & 0.17 & 0.08 & 0.18 \\
\hline Low income $(<39 \mathrm{k}$ euro $)$ & 0.56 & 0.44 & -0.35 \\
\hline High income ( $>78 \mathrm{k}$ euro) & $-0.71^{* *}$ & $-0.71^{* *}$ & -0.01 \\
\hline Low wealth $(<50 \mathrm{k}$ euro $)$ & 0.55 & 0.49 & 0.49 \\
\hline High wealth (> 50k euro) & $-0.72^{* * *}$ & -0.42 & -0.26 \\
\hline DHS panel member & $0.45^{*}$ & 0.10 & -0.50 \\
\hline AFM respondent recruited by GfK & 0.20 & 0.02 & -0.21 \\
\hline Pseudo-R2 & 0.135 & 0.104 & 0.108 \\
\hline Observations & 322 & 309 & 327 \\
\hline
\end{tabular}

multiple brokerage accounts such that data from one particular account may represent only a fraction of an investor's total portfolio and trading behavior. For example, an investor could be passively investing in a portfolio of mutual funds in one account, but actively churning lottery-type stocks in another brokerage account. Our survey data represents the investors' overall portfolio and trading behavior, overcoming this limitation. Further, existing studies analyzing trading records from one particular broker may inadvertently sample a subgroup of more active investors that is substantially different from the complete population, whereas our data represents all Dutch investors. DHS survey data was used previously in well-known studies of household portfolios, such as Van Rooij et al. (2011) and Von Gaudecker (2015).

\section{Conclusions}

We estimate the prevalence of compulsive gambling in the financial markets, in a representative sample of Dutch investors. Our results reveal that $4.4 \%$ of the Dutch retail investors show symptoms of compulsive gambling, or an addiction to trading, with a $95 \%$ confidence interval of $[2.5 \%, 7.0 \%]$. Another $3.6 \%$ of the investors display symptoms of problem gambling ([1.9\%, 6.0\%]), which is less a severe condition, but still worrisome.

We validate the compulsive gambling scale by testing whether investors with compulsive gambling symptoms pursue more active and speculative trading styles. Our results show that the compulsive gambling scale is strongly correlated with speculative trading behavior, beyond factors like overconfidence, risk tolerance, financial literacy and trading experience. We compare the compulsive gambling screen to direct and indirect proxies for gambling motives such as trading for fun, trading for a small chance to become rich, and participating in conventional gambling activities (casinos, sports betting, etc.). We find that investors with more innocuous gambling motives, like trading for fun or a chance to become rich, do not display more active trading behavior.
Our results show that the APA DSM-5 screen for compulsive gambling isolates a relatively small subgroup of investors and is the best predictor for speculative trading behavior, which is essential for practical purposes. Investors with compulsive gambling tendencies are also in a worse financial situation compared to other investors and have more financial problems, after controlling for socio-demographic characteristics.

Our data also reveal that the large majority of investors in the Dutch population trade stocks less than 10 times a year, and do not invest in derivatives or leveraged products. Only a small group of investors follow more active and speculative trading strategies, with day-trading and investing in derivatives being common strategies pursued by about one out of five (20\%) direct investors. Screening for compulsive gambling may help to further identify and separate the small group of investors who trade actively because they cannot resist or stop their urge to gamble in financial markets. In our sample, one out of 23 direct investors (4.4\%) display symptoms of compulsive trading in financial markets.

Future research could shed more light on the causes and consequences of compulsive gambling in the financial markets, and test to what extent gambling-motivated trading is influenced by past gains and losses. Moreover, since gambling behavior is strongly influenced by local norms and regulations (Kumar et al., 2011), further work can test the generalizability of our findings to other countries. For example, an open question is whether compulsive gambling in the financial markets is more or less widespread in countries where conventional gambling activities are more strictly regulated.

\section{Acknowledgment}

We thank Daniel Dorn, Kim Peijnenburg and seminar participants at Bank of Thailand, Erasmus University Rotterdam and New Zealand Finance Colloquium for valuable comments. The authors gratefully acknowledge financial support from Netspar and ERIM for data collection in the DHS household panel, and support from 
the Dutch Authority for Financial Markets for data collection in the AFM panel. The views expressed in this paper are solely those of the authors.

\section{Appendix A. Selected survey questions}

\section{A.1. Investment objectives}

Our survey asks investors to indicate their investment objectives, choosing from seven possible answers (multiple answers are allowed):

1. Saving for retirement, or to generate additional income.

2. Saving for a special expense (e.g., a new car or vacation).

3. Saving for a specific purpose, such as mortgage prepayment, or the kids' education.

4. Preserving my wealth. The money is not needed for any specific goal or expense, and it should just maintain its value.

5 . The fun or challenge of investing.

6. Investing gives me a small chance to get rich, and I am willing to take risk for this purpose.

7. Another purpose (an open response category).

\section{A.2. DOSPERT gambling risk-taking propensity}

The DOSPERT scale consists of the following four questions: How likely is it that you will participate in the following activities?

1. Betting with 100 euro or more on a slot machine.

2. Betting with 100 euro or more in a poker game, or in an online casino game.

3. Betting with 100 euro or more on the result of sports game, or in a sports betting pool.

4. Betting with 500 euro or more in a casino.

Each question is answered on this 5-point scale:

1. Very unlikely, 2. Unlikely, 3. Neither likely, nor unlikely, 4. Likely, 5. Very Likely.

\section{A.3. APA DSM-5 compulsive gambling criteria adopted to financial markets}

The following questions are about your of trading of financial products, such as individual company stocks, ETF's (index trackers), derivatives and leveraged products (such as turbo's, speeders, binary options and contracts for differences). While answering these questions please consider your actual trading activities during the last 12 months.

1. You trade financial products with larger amounts of money to maintain the excitement.

2. You have to borrow money from family members or friends to cover the losses from trading in financial products.

3. You always think of ways to get money to trade financial products.

4. You lie to your family or friends about your trading in financial products.

5. You tried to reduce your trading of financial products, or to quit altogether, but could not.

6. You trade financial products to escape problems in your life.

7. You trade more in order to win back your previous losses.

8. You have problems in your work, with family members or with your partner as a consequence of your trading in financial products.

9. You become irritated when trying to reduce or quit trading financial products.

The response scale for each question is: 1. Never, 2. Sometimes.

3. Often, 4. All the time.
We count the answers "Sometimes", "Often" and "All the time" as 1 , and "Never" as 0 , when counting the number of compulsive gambling symptoms of the respondents.

\section{A.4. Financial situation questions}

Question 1: What is your current financial situation?

1. I have a lot of money leftover

2. I have some money leftover

3. I make ends meet exactly

4. I am slightly dipping into my savings

5. I am running into debt

Question 2: How easy is it for you to make ends meet?

1. Very easy

2. Easy

3. Neither easy nor difficult

4. Difficult

5. Very Difficult

Question 3: Did your household experience any of the following events in the past twelve months?

1. Payment of bills overdue

2. Received a payment reminder

3. Unable to draw money from your checking account

4. Automatic transfer was refused

5. Received payment notices from a debt collection agency

6. More than 10 days late with rental or mortgage payments

7. Seizure of income

8. Late payment of health insurance premium

The answer scale for all eight financial problem questions is:

1. No, 2. Yes, sometimes, 3. Yes, regularly, 4. Not applicable, 5. Don't know/Refuse to answer

\section{A.5. Financial literacy questions}

Question 1: Suppose that you have 100 euro on a savings account and the interest is $20 \%$ per year, and you never withdraw the money or interest. How much do you have on the account after 5 years?

(a) More then 200 euro, (b) Exactly 200 euro, (c) Less than 200 euro, (d) I do not know, (e) Refuse to answer

Question 2: Suppose the interest on your savings account is 1\% per year and the inflation is $2 \%$ per year. After 1 year, can you buy more, exactly the same, or less than today with the money on the account?

(a) More than today, (b) Exactly the same as today, (c) Less than today, (d) I do not know, (e) Refuse to answer

Question 3: Is the following statement true, or not true?

'A company stock usually provides a less risky return than an equity mutual fund.'

(a) True, (b) Not true, (c) I do not know, (d) Refuse to answer

\section{References}

American Psychiatric Association, 2013. Diagnostic and Statistical Manual of Mental Disorders (DSM-5). American Psychiatric Publishing, Washington, DC.

Arthur, J.N., Williams, R.J., Delfabbro, P.H., 2016. The conceptual and empirical relationship between gambling, investing, and speculation. J. Behav. Addict. 5 (4), 580-591.

Bali, T.G., Brown, S.J., Murray, S., Tang, Y., 2017. A lottery-demand-based explanation of the beta anomaly. J. Financ. Quant. Anal. 52 (6), 2369-2397.

Barber, B.M., Odean, T., 2000. Trading is hazardous to your wealth: the common stock investment performance of individual investors. J. Financ. 55 (2), 773-806.

Barber, B.M., Odean, T., 2001. Boys will be boys: gender, overconfidence, and common stock investment. Q. J. Econ. 116 (1), 261-292. 
Barber, B.M., Lee, Y.T., Liu, Y.J., Odean, T., 2014. The cross-section of speculator skill: evidence from day trading. J. Financ. Mark. 18, 1-24.

Bauer, R., Cosemans, M., Eichholtz, P., 2009. Option trading and individual investor performance. J. Bank. Financ. 33 (4), 731-746.

Black, F., 1986. Noise. J. Financ. 41 (3), 528-543.

Blaszczynski, A., Nower, L., 2002. A pathways model of problem and pathological gambling. Addiction 97 (5), 487-499.

Conlisk, J., 1993. The uility of gambling. J. Risk Uncertain. 6 (3), 255-275.

Dohmen, T., Falk, A., Huffman, D., Sunde, U., Schupp, J., Wagner, G.G., 2011. Individual risk attitudes: measurement, determinants, and behavioral consequences. J. Eur. Econ. Assoc. 9 (3), 522-550.

Dorn, D., Sengmeuller, P., 2009. Trading as entertainment? Manag. Sci. 55 (4), 591-603.

Dorn, A.J., Dorn, D., Sengmueller, P., 2015. Trading as gambling. Manag. Sci. 61 (10), 2376-2393.

Engelberg, J., Parsons, C.A., 2016. Worrying about the stock market: evidence from hospital admissions. J. Financ. 71 (3), 1227-1250.

Entrop, O., McKenzie, M., Wilkens, M., Winkler, C., 2016. The performance of individual investors in structured financial products. Rev. Quant. Financ. Acc. 46 (3), 569-604.

Filippou, I., Garcia-Ares, P.A., Zapatero, F. (2018). Demand for lotteries: the choice between stocks and options, Working paper.

Gao, X., Lin, T.C., 2015. Do individual investors treat trading as a fun and exciting gambling activity? evidence from repeated natural experiments. Rev. Financ. Stud. 28 (7), 2128-2166.

Gerstein, D., Volberg, R.A., Toce, M.T., Harwood, H., Johnson, R.A., Buie, T., Hill, M.A., 1999. Gambling Impact and Behavior Study: Report to the National Gambling Impact Study Commission. National Opinion Research Center, Chicago.

Glaser, M., Weber, M., 2007. Overconfidence and trading volume. Geneva Risk Insur. Rev. 32 (1), 1-36.

Goudriaan, A.E., 2014. Gambling and problem gambling in the Netherlands. Addiction 109 (7), 1066-1071.

Grall-Bronnec, M., Sauvaget, A., Boutin, C., Bulteau, S., Jiménez-Murcia, S., Fernández-Aranda, F., Challet-Bouju, G., Caillon, J., 2017. Excessive trading, a gambling disorder in its own right? A case study on a French disordered gamblers cohort. Addict. Behav. 64, 340-348.

Granero, R., Tárrega, S., Fernández-Aranda, F., Aymamí, N., Gómez-Peña, M., Moragas, L., Jiménez-Murcia, S., 2012. Gambling on the stock market: an unexplored issue. Compr. Psychiatry 53 (6), 666-673.

Grinblatt, M., Keloharju, M., 2009. Sensation seeking, overconfidence, and trading activity. J. Financ. 64 (2), 549-578.

Han, B., Kumar, A., 2013. Speculative retail trading and asset prices. J. Financ. Quant. Anal. 48 (2), 377-404.
Hoffmann, A.O., Shefrin, H., 2014. Technical analysis and individual investors. J. Econ. Behav. Org. 107, 487-511.

Horvath, P., Zuckerman, M., 1993. Sensation seeking, risk appraisal, and risky behavior. Person. Individ. Diff. 14 (1), 41-52.

Kahneman, D., Tversky, A., 1979. Prospect theory: an analysis of decision under risk. Econometrica 47 (2), 263-292.

Kamolsareeratana, A., Kouwenberg, R. (2019). Compulsive gambling in the stock market, Working paper.

Kumar, A., 2009. Who gambles in the stock market? J. Financ. 64 (4), 1889-1933.

Kumar, A., Page, J.K., Spalt, O.G., 2011. Religious beliefs, gambling attitudes, and financial market outcomes. J. Financ. Econ. 102 (3), 671-708.

Kumar, A., Page, J.K., Spalt, O.G., 2016. Gambling and comovement. J. Financ. Quant Anal. 51 (1), 85-111.

Ladouceur, R., Boisvert, J.M., Pépin, M., Loranger, M., Sylvain, C., 1994. Social cost of pathological gambling. J. Gambl. Stud. 10 (4), 399-409.

Lusardi, A., Mitchell, O.S., 2007. Baby boomer retirement security: the roles of planning, financial literacy, and housing wealth. J. Monet. Econ. 54 (1), 205-224.

Markiewicz, Ł., Weber, E.U., 2013. DOSPERT's gambling risk-taking propensity scale predicts excessive stock trading. J. Behav. Financ. 14 (1), 65-78.

Mills, D.J., Nower, L., 2019. Preliminary findings on cryptocurrency trading among regular gamblers: a new risk for problem gambling? Addict. Behav. 92, 136-140.

Odean, T., 1999. Do investors trade too much? Am. Econ. Rev. 89 (5), 1279-1298.

Shin, Y.C., Choi, S.W., Ha, J., Choi, J.S., Kim, D.J., 2015. Gambling disorder in financial markets: clinical and treatment-related features. J. Behav. Addict. 4 (4), 244-249.

Statman, M., 2002. Lottery players/stock traders. Financ. Anal. J. 58 (1), 14-21.

Stucki, S., Rihs-Middel, M., 2007. Prevalence of adult problem and pathological gambling between 2000 and 2005: an update. J. Gambl. Stud. 23 (3), 245-257.

Van Rooij, M., Lusardi, A., Alessie, R., 2011. Financial literacy and stock market participation. J. Financ. Econ. 101 (2), 449-472.

Volberg, R.A., 2001. When the Chips are Down: Problem Gambling in America. The Century Foundation Press, New York.

Von Gaudecker, H., 2015. How does household portfolio diversification vary with financial sophistication and advice. J. Financ. 70 (2), 489-507.

Weber, E.U., Blais, A.R., Betz, N.E., 2002. A domain-specific risk-attitude scale: measuring risk perceptions and risk behaviors. J. Behav. Decis. Mak. 15 (4), 263-290.

Welte, J.W., Barnes, G.M., Tidwell, M.C.O., Hoffman, J.H., Wieczorek, W.F., 2015. Gambling and problem gambling in the united states: changes between 1999 and 2013. J. Gambl. Stud. 31 (3), 695-715.

Youn, H., Choi, J.S., Kim, D.J., Choi, S.W., 2016. Development and validation of a stock addiction inventory (SAI). Ann. Gen. Psychiatry 15 (1), 16.

Zuckerman, M., 1994. Behavioral Expressions and Biosocial Bases of Sensation Seeking. Cambridge University Press. 